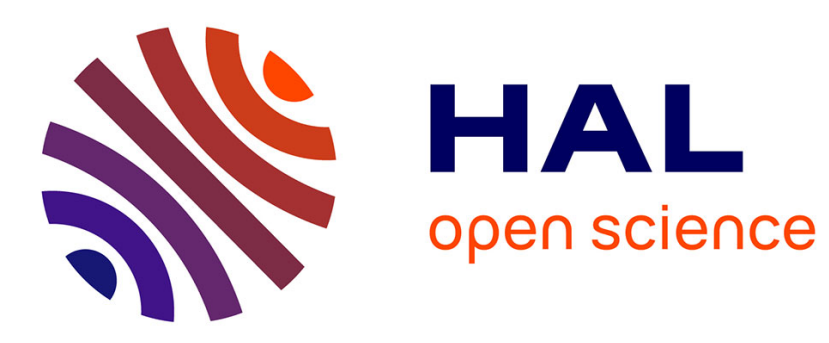

\title{
On the scaling of EMFI probes
}

Julien Toulemont, Geoffrey Chancel, Jean-Marc J.-M. Galliere, Frédérick

Mailly, Pascal Nouet, Philippe Maurine

\section{To cite this version:}

Julien Toulemont, Geoffrey Chancel, Jean-Marc J.-M. Galliere, Frédérick Mailly, Pascal Nouet, et al.. On the scaling of EMFI probes. FDTC 2021 - Workshop on Fault Detection and Tolerance in Cryptography, Sep 2021, Milan, Italy. pp.67-73, 10.1109/FDTC53659.2021.00019 lirmm-03476820

\section{HAL Id: lirmm-03476820 \\ https://hal-lirmm.ccsd.cnrs.fr/lirmm-03476820}

Submitted on 13 Dec 2021

HAL is a multi-disciplinary open access archive for the deposit and dissemination of scientific research documents, whether they are published or not. The documents may come from teaching and research institutions in France or abroad, or from public or private research centers.
L'archive ouverte pluridisciplinaire HAL, est destinée au dépôt et à la diffusion de documents scientifiques de niveau recherche, publiés ou non, émanant des établissements d'enseignement et de recherche français ou étrangers, des laboratoires publics ou privés. 


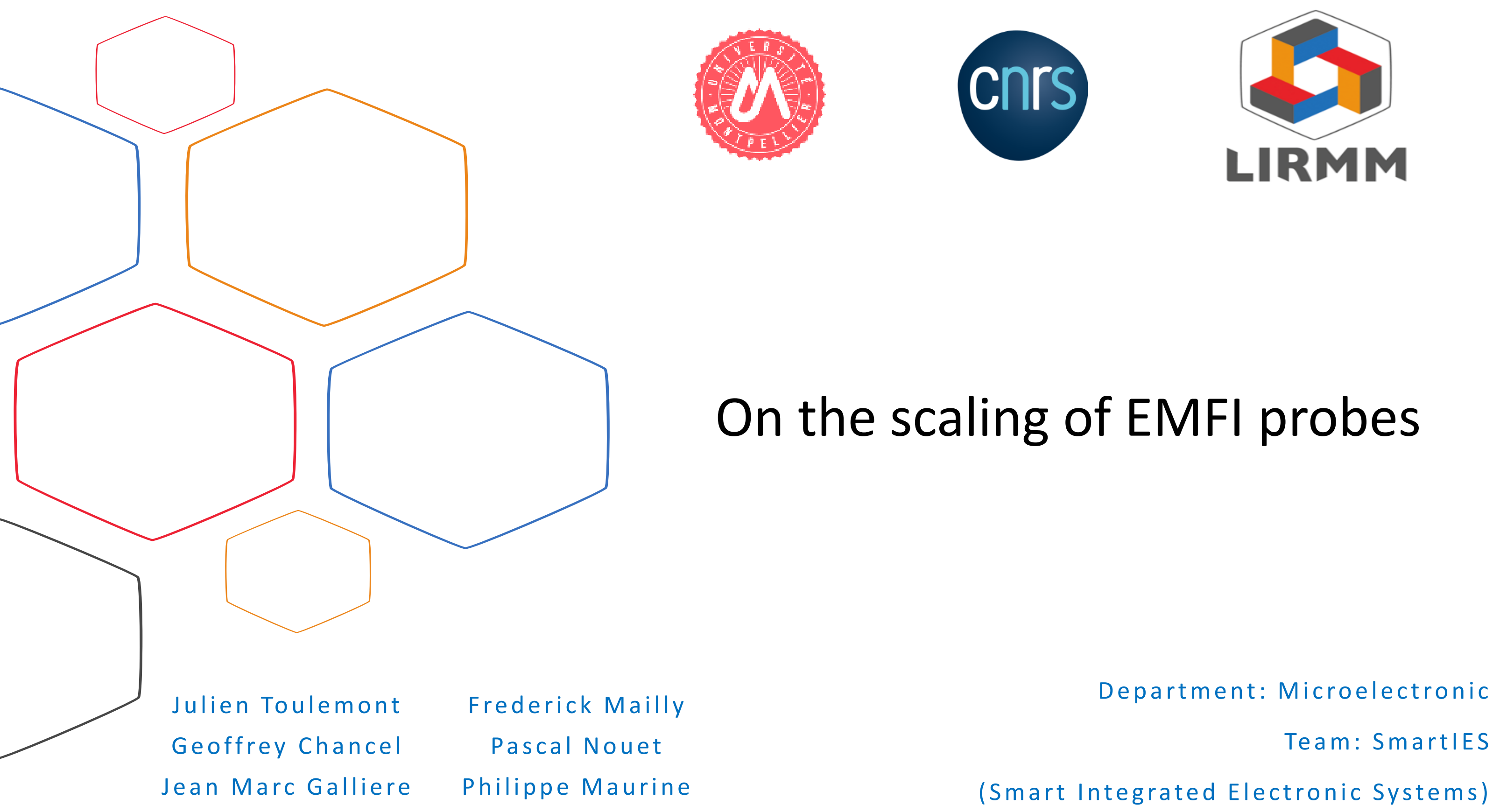




\section{Outline}

- Context \& Motivation

- EM fault induction principle

- Scaling factor (theoretical calculation)

- EMFI platform

- Experimental results

- Conclusion 


\section{Introduction}

- Main drawbacks of EMFI are:

- Its limited spatial resolution

- Impact on several blocks leading to IC crashes

- Increasing the spatial resolution implies reducing the EM probes dimension

$\Rightarrow$ Reducing their self inductance

$\Rightarrow$ Reducing the EM coupling between the probe and the circuit

$\Rightarrow$ More powerful voltage pulse generator

What is the cost?

How to choose the appropriate pulse generator?

How to reduce the probes dimension?

How to set the appropriate pulse when changing the probe? 


\section{EM fault induction principle}

- EMFI exploits the EM coupling between a probe and the power and ground networks of ICS

- EM couplings modelling: $M=k \cdot \sqrt{L_{P} \cdot L_{G}}$

- $V_{p}$ applied to the probe induces $V_{\text {ind }}$ along each square loop of the power and ground networks:

$$
V_{\text {ind }}=M \cdot \frac{1}{R_{P}} \cdot \frac{\Delta V_{P}}{\Delta t}=M \cdot \frac{1}{R_{P}} \cdot \frac{V_{P}}{\Delta t}
$$

- Having the same effect with probe 1 and 2:

$$
\frac{M_{1}}{M_{2}}=\frac{\Delta V_{P 2}}{\Delta V_{P 1}}=\frac{V_{P 2}}{V_{P 1}}
$$

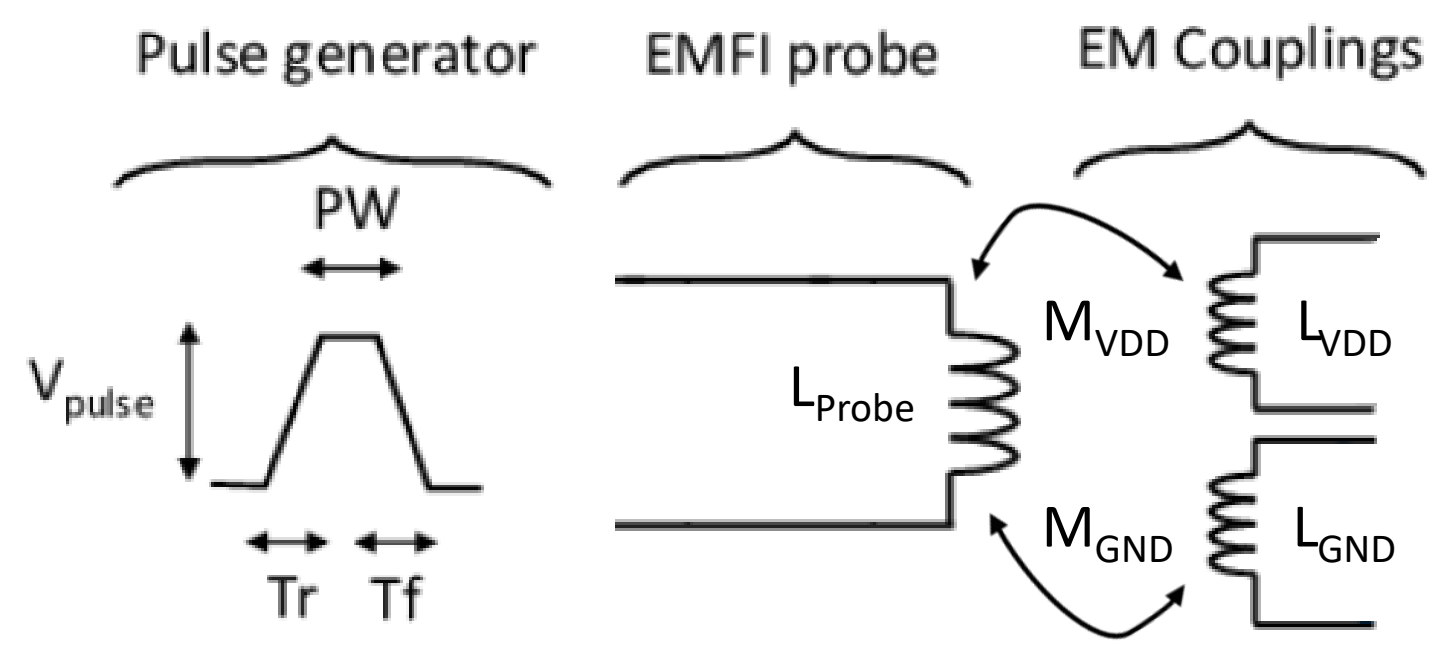




\section{Scaling down of EMFI probes dimension}

- Self inductance of a square shape probe of side length $\mathrm{W}$ :

$$
L_{p}=\frac{2 \cdot N \cdot \mu_{0} \cdot W}{\pi}\left[\log \left(\frac{W}{R}\right)-0.524\right]
$$

- Same effect if :

$$
\frac{V_{P 2}}{V_{P 1}}=\sqrt{\frac{W_{1} \cdot\left[\log \left(\frac{W_{1}}{R}\right)-0.524\right]}{W_{2} \cdot\left[\log \left(\frac{W_{2}}{R}\right)-0.524\right]}}
$$

- An approximation of the scaling factor is:

$$
\frac{V_{P 2}}{V_{P 1}} \simeq \sqrt{\frac{W_{1}}{W_{2}}}
$$

- Self inductance of a circular shape probe of diameter a:

$$
L_{p}=\frac{N \cdot \mu_{0} \cdot a}{\pi}\left[\log \left(\frac{8 \cdot a}{R}\right)-1.75\right]
$$

- Same effect if :

$$
\frac{V_{P 2}}{V_{P 1}}=\sqrt{\frac{a_{1} \cdot\left[\log \left(\frac{a_{1}}{R}\right)-1.75\right]}{a_{2} \cdot\left[\log \left(\frac{a_{2}}{R}\right)-1.75\right]}}
$$

- An approximation of the scaling factor is:

$$
\frac{V_{P 2}}{V_{P 1}} \simeq \sqrt{\frac{a_{1}}{a_{2}}}
$$

The power of pulse generator of EMFI platforms must be scaled proportionately to the square root of the probe dimensions 


\section{EMFI platform equipment}

- Voltage pulse generator

- AVRK4 from Avtech

- Pulse ranging from $100 \mathrm{~V}$ to $750 \mathrm{~V}$

- Designed to drive $50 \Omega$ loads

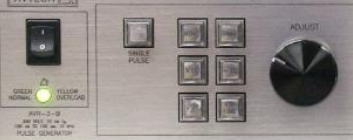

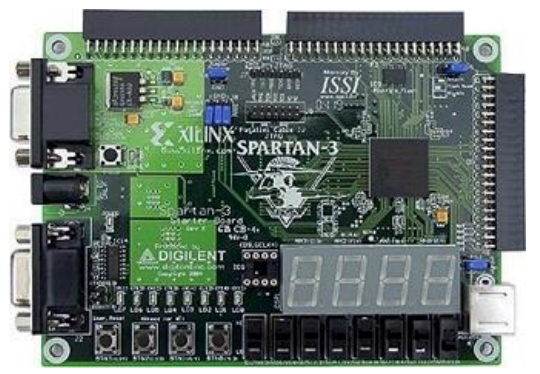

- Anti-bounce system

- Impedance of the EM probes below $1 \Omega=>$ Impedance mismatch with the pulse generator

- Signal bounces between the output of the generator and the input of the probes

- Limitation of the timing resolution of the platform 


\section{Anti-bounce system}

- High speed unidirectional Transil diode:

$$
\mathrm{V}_{\mathrm{BR}}=570 \mathrm{~V} \quad \mathrm{~V}_{\text {clamp }}=860 \mathrm{~V} \quad \mathrm{~V}_{\mathrm{F}}=1 \mathrm{~V}
$$

- The pulse propagating from $V^{+}$to $V^{-}$still gets across the probe if: $\quad V_{p}=\left(V^{+}-V^{-}\right)<V_{B R}$

- The reflected pulse is dissipated by the Transil diode if:

$$
\alpha \cdot V_{p}=\left(V^{-}-V^{+}\right)>V_{F} \text { with } \alpha \in[0,1]
$$

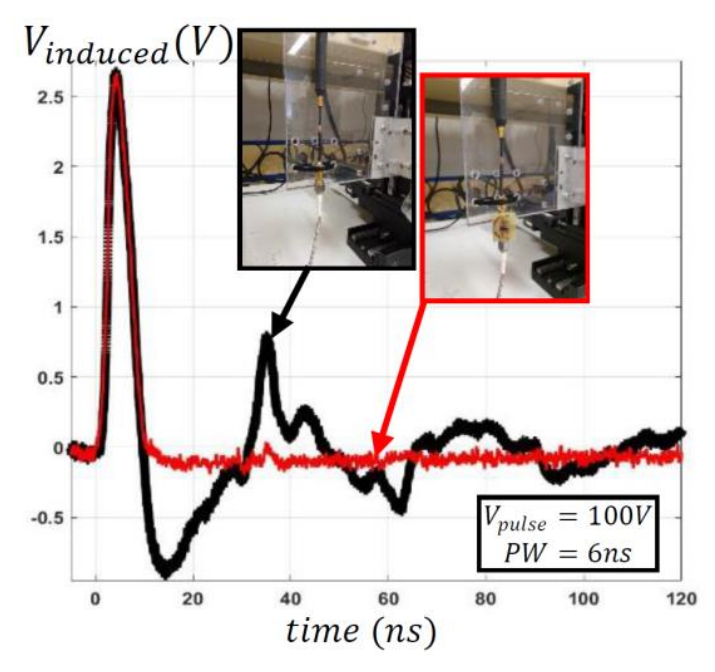

Measured perturbations induced in a RF3mini probe from Langer (with the same voltage pulse generator settings)
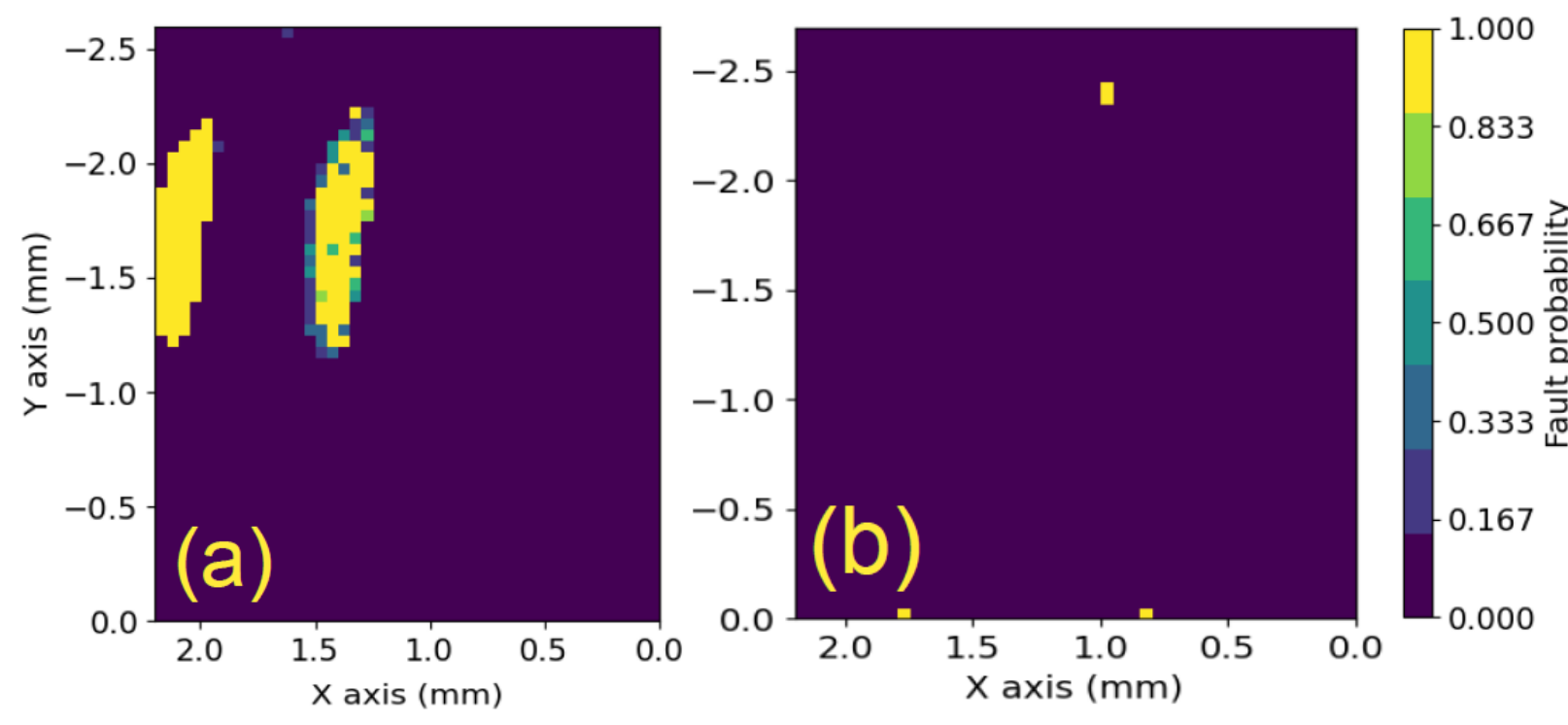

Fault probability maps obtained (a) with and (b) without the anti-bounce system for $V p=450 \mathrm{~V}$ and $P W=10 \mathrm{~ns}$
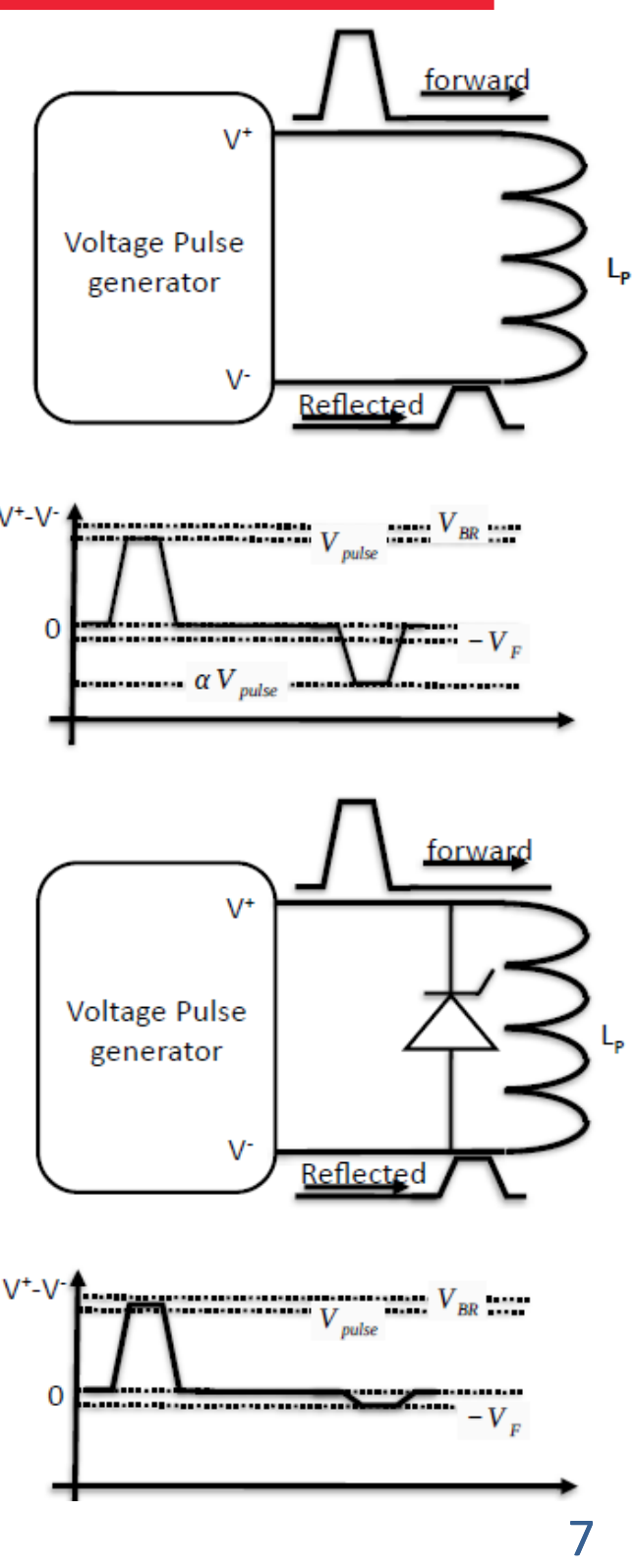


\section{Probes}

- Advanced flexible electronic technology

- Flexible PCB characteristics:

- $50 \mu \mathrm{m}$ metal lines

- $50 \mu \mathrm{m}$ metal spacing

- 4 layers

- Initial probes for EM fault injection:

- 2.5 rectangular turns

- Side length $W=300 \mu \mathrm{m}, 400 \mu \mathrm{m} \& 650 \mu \mathrm{m}$

- With and without a ferrite core

- Additional probes:

- 1 or 2 loops

- $\quad$ Side length $W=150 \mu \mathrm{m}, 100 \mu \mathrm{m} \& 50 \mu \mathrm{m}$

- Without ferrite core because initially designed for electromagnetic analysis

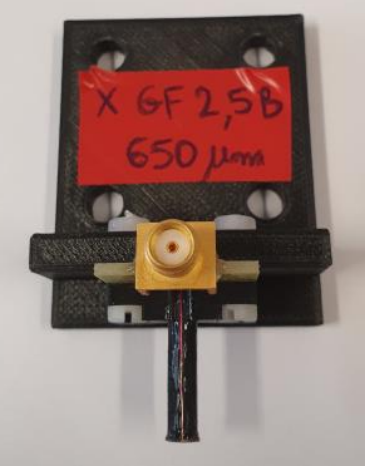

$\emptyset 650 \mu m$ probe

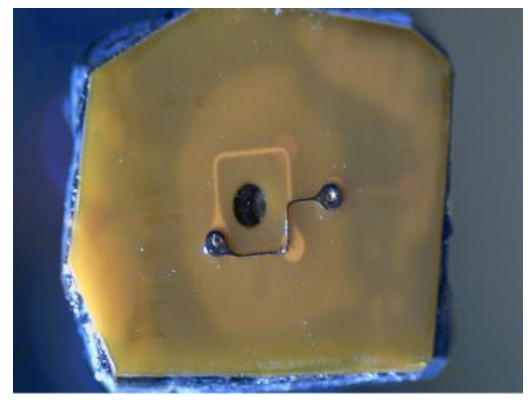

$\emptyset 650 \mu m$

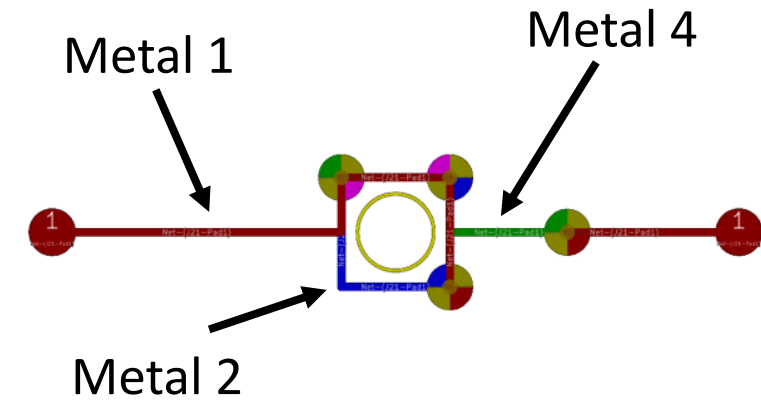

Flexible PCB layout
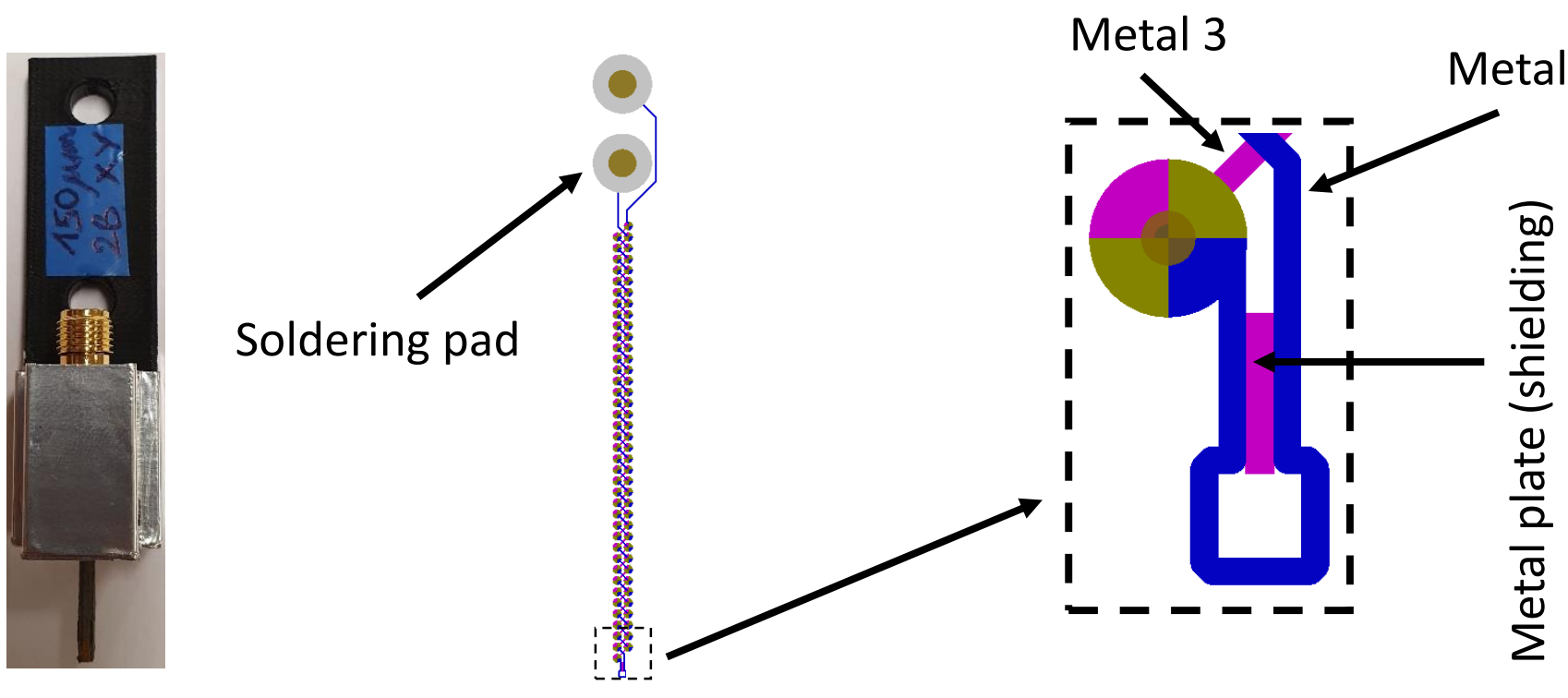

Flexible PCB layout 


\section{$V p_{\text {min }}$ maps}

- Near field scans of the same part of the IC surface with the 3 initial probes for EMFI

- Measurement of $V p_{\text {min }}$ to be applied to the probe, at each coordinate, to induce a fault:

- Displacement step: $100 \mu \mathrm{m}$

- Vp range: [100V;500V]

- Vp step: $20 \mathrm{~V}$

- We consider the minimum of $\mathrm{Vp}_{\min }$ values of each histogram as values robust to map misalignment, so we computed:

$$
\frac{V_{P 2}^{E x p}}{V_{P 1}^{E x p}} \simeq \frac{\min \left(V_{P 2}^{\min }\right)}{\min \left(V_{P 1}^{\min }\right)}
$$
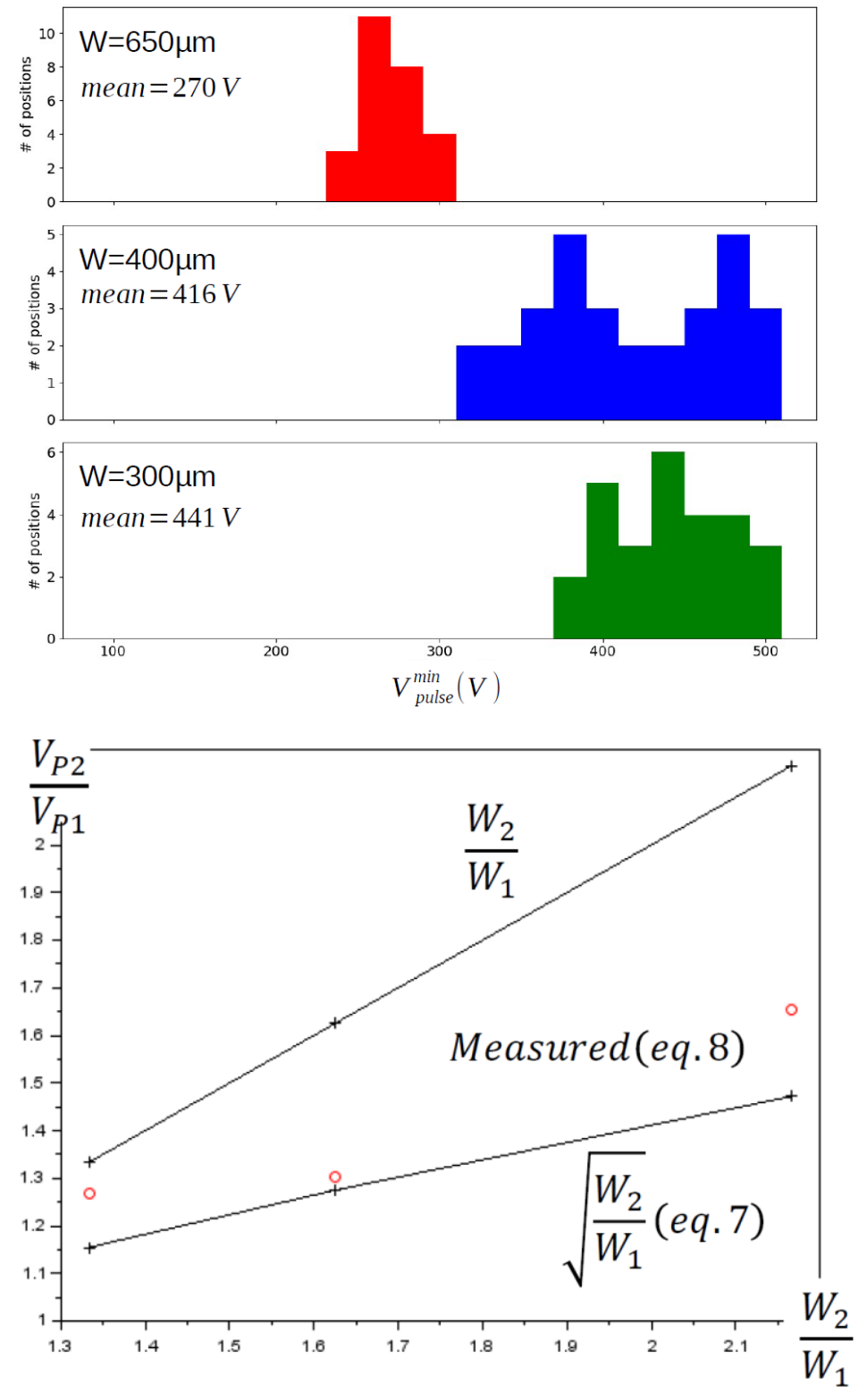


\section{Fault probability maps with different probes}

- Circuit scan:

- $6 \mathrm{EMFI}$ at each probe position

- Displacement step of $50 \mu m$

- 6 probes $(650 \mu \mathrm{m}, 400 \mu \mathrm{m}, 300 \mu \mathrm{m}, 150 \mu \mathrm{m}, 100 \mu \mathrm{m}$ and $50 \mu \mathrm{m})$

- Probe placed at a distance $Z=50 \mu \mathrm{m}$ from the IC surface

- Reprogramming of the FPGA after the occurrence of each fault to avoid the effect of persistent faults

- Red pixels correspond to positions where EMFI induces a crash (no response) of the device under EMFI 


\section{Fault probability maps with different probes}
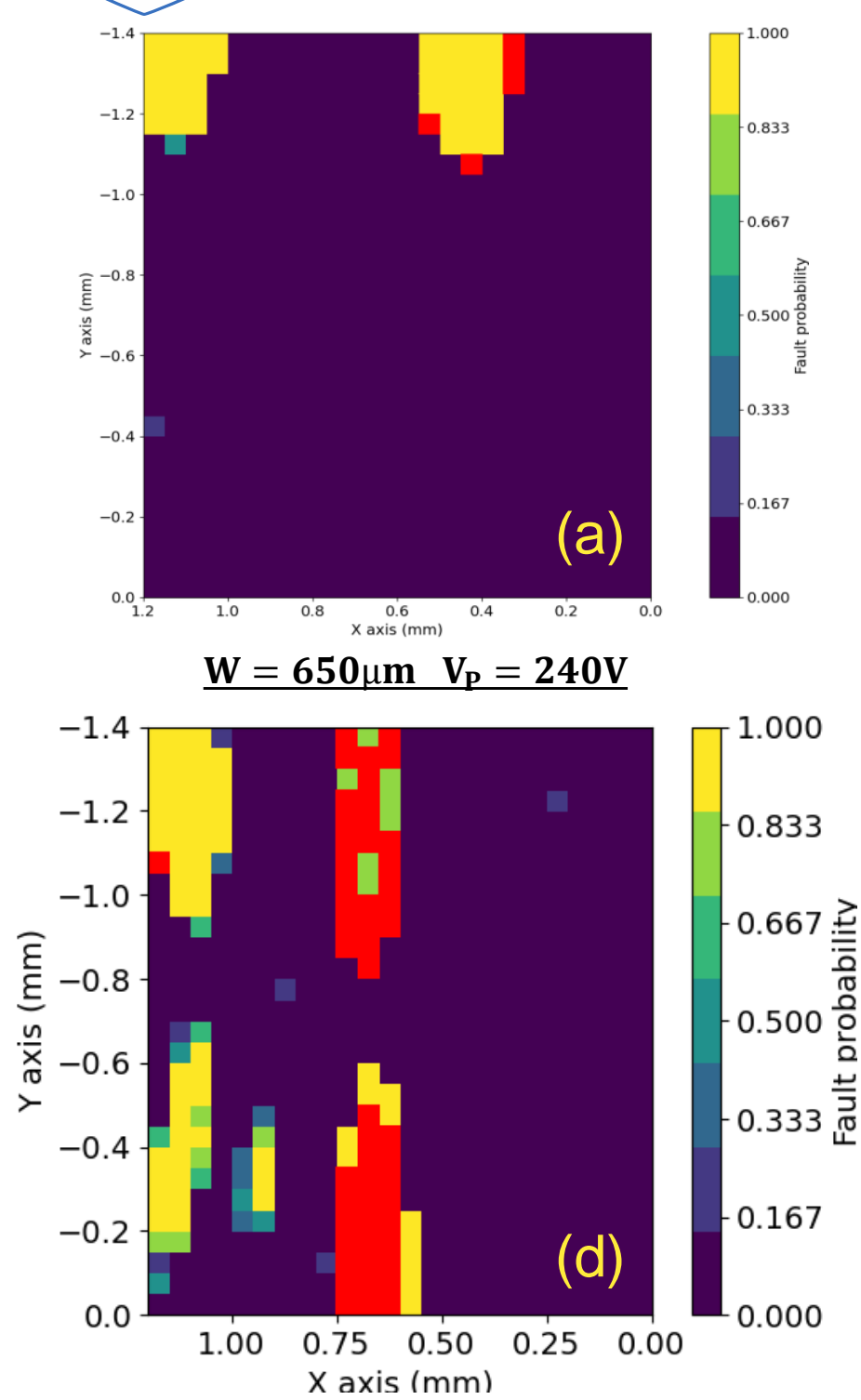

$\underline{W}=150 \mu \mathrm{m} \quad V_{p}=520 \mathrm{~V}$

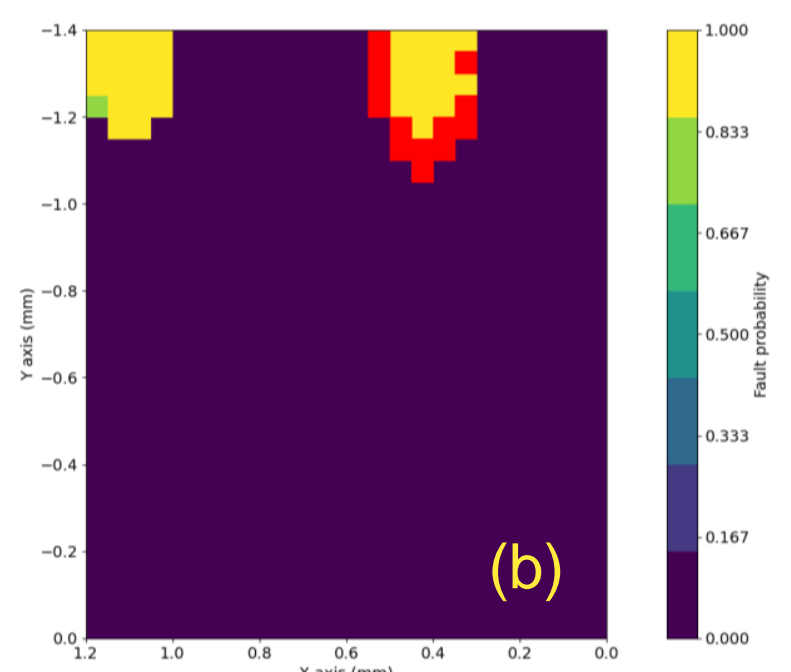

$\underline{\mathbf{W}}=\mathbf{4 0 0} \mu \mathrm{m} \quad V_{\mathbf{P}}=\mathbf{3 3 0 V}$

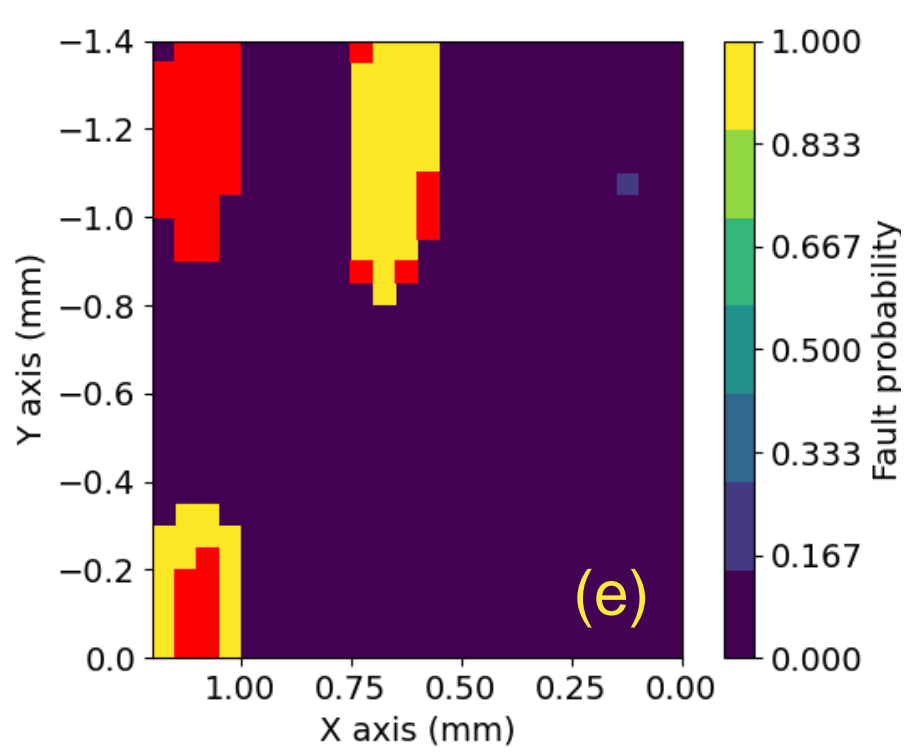

$\underline{W}=100 \mu \mathrm{m} \quad V_{P}=630 \mathrm{~V}$
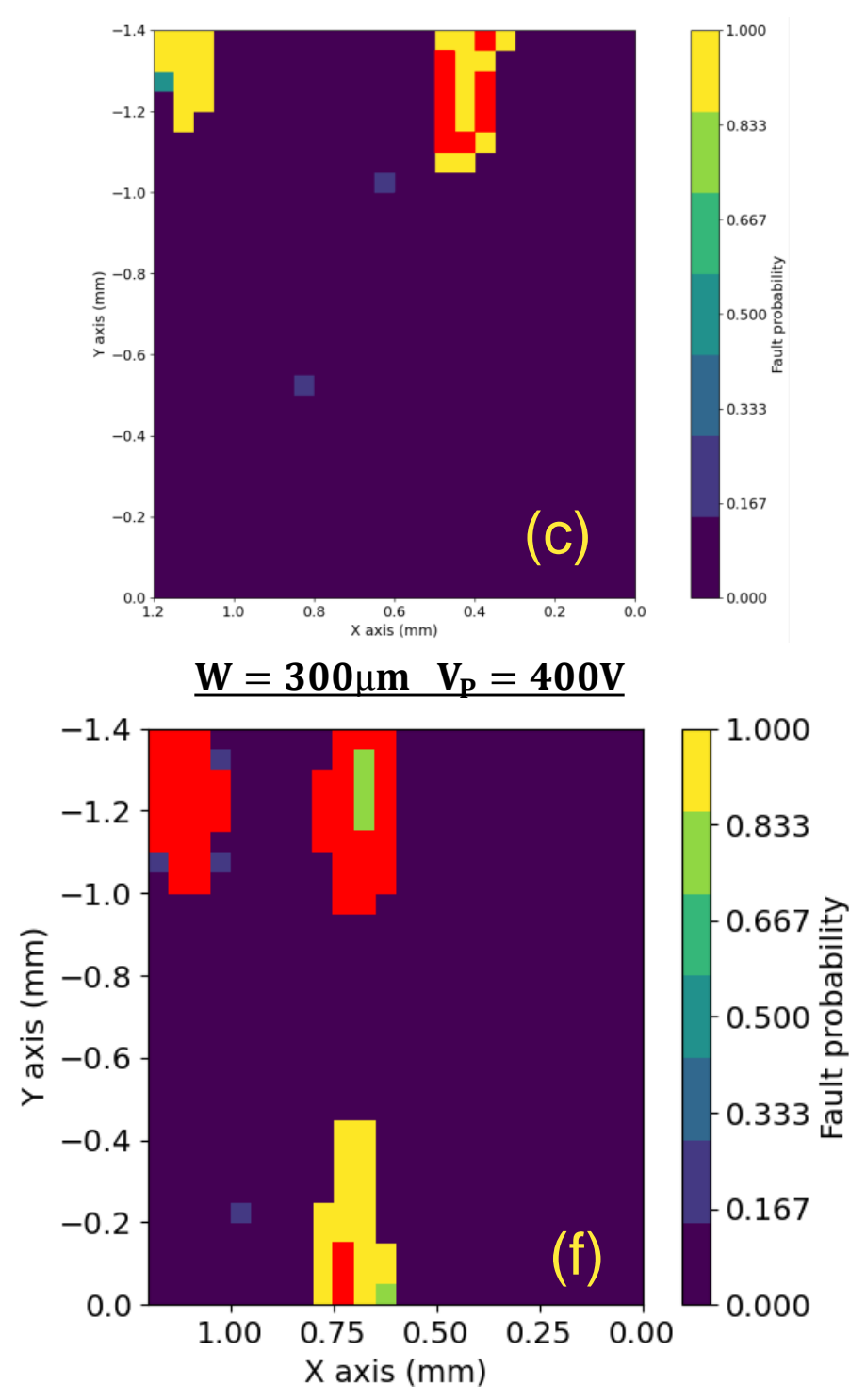

$\underline{W}=50 \mu m \quad V_{p}=780 V$ 


\section{LIRMM progress}

2014
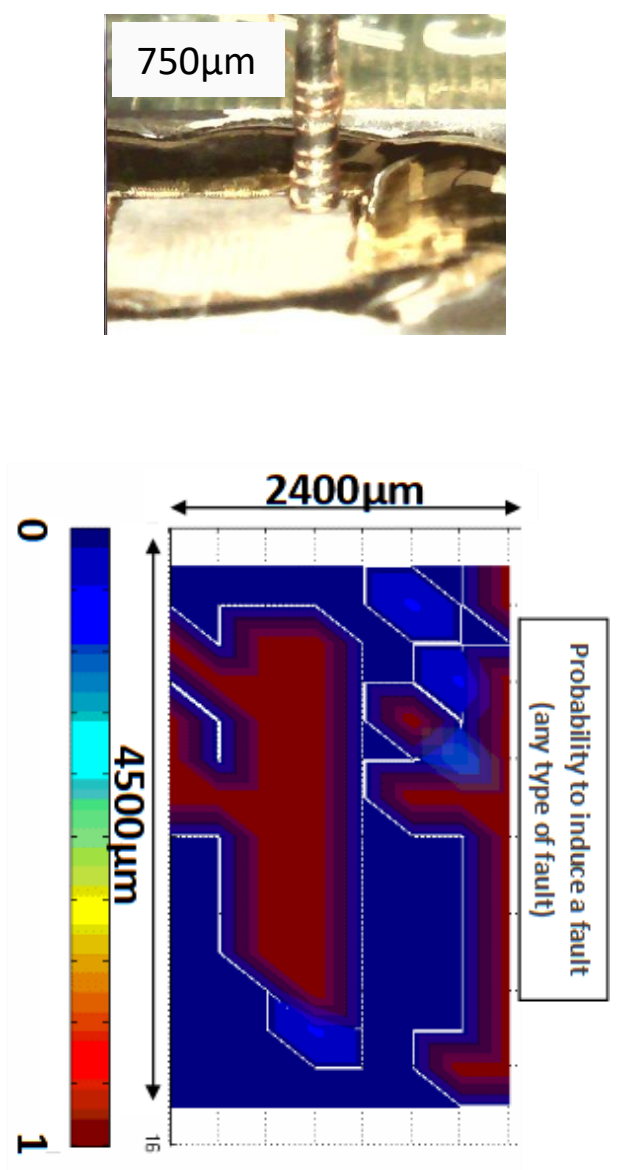

2021

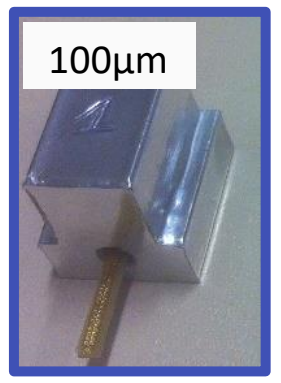

Same device

Same experimentation

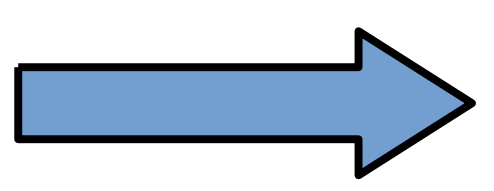

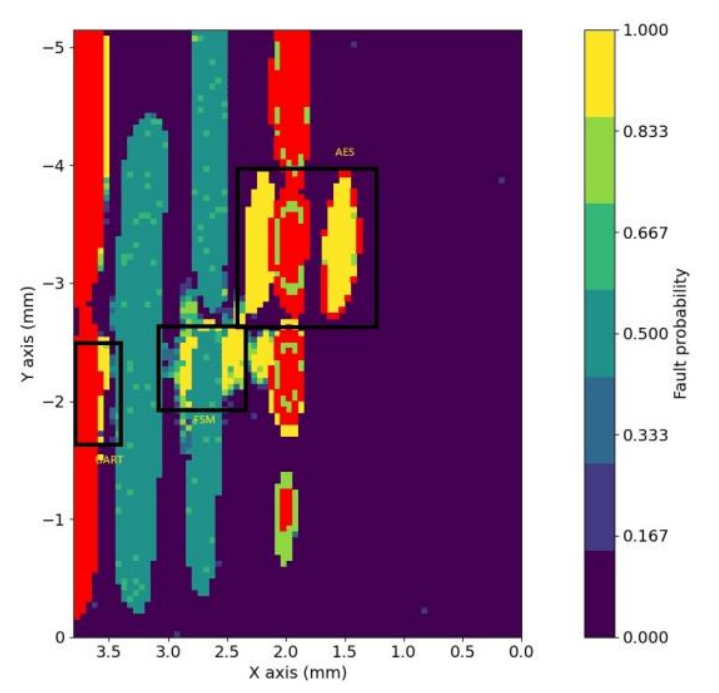




\section{Conclusion}

- The effect of scaling down the dimension of EMFI probes has been studied both theoretically and experimentally

- It is possible to increase EMFI spatial resolution

- It is possible to design low cost EMFI probes using flexible electronics combined with 3D printing

- The power of pulse generator required to use such probes is not so high

$\Rightarrow$ The scaling with probe dimension follows a square root law 
Thank you for your attention!

Any questions? 